\title{
Challenges and Determinants of the Use of Renewable Energy, Special Reference to the Selected Woreda of Assosa and Metekel Zones, Benishangul Gumuz Region
}

\author{
Yohannes Feyissa Beyisho \\ Department of Mechanical Engineering, Assosa University, Benishangul Gumuz, Ethiopia \\ Email address: \\ yonna2626@gmail.com \\ To cite this article: \\ Yohannes Feyissa Beyisho. Challenges and Determinants of the Use of Renewable Energy, Special Reference to the Selected Woreda of \\ Assosa and Metekel Zones, Benishangul Gumuz Region. Engineering and Applied Sciences. Vol. 5, No. 4, 2020, pp. $79-82$. \\ doi: $10.11648 /$ j.eas. 20200504.12
}

Received: June 12, 2020; Accepted: July 24, 2020; Published: August 10, 2020

\begin{abstract}
The Known importance of renewable energy in the discussion of a reliable and sustainable energy future, it is imperative to understand its main determinants and hindering factors and to draw result implications for energy policy and to overcome the challenges. This Research surveys about the determinants and challenges of the use of Renewable Energy, with Special Reference to, Benishangul Gumuz Regional State selected zonal Woredas (Assosa Zone and Metekel Zone). Using HOMER SOFTWARE and the EXCEL spread sheet, for a period covering 2008-2016, the results suggest that the community under study mainly relay on the Energy source of hydropower covers mostly $58.59 \%$ of the total energy consumption of the inhabitants. Also the finding indicates the inhabitants mostly relay on gas oils for energy sources with the percentage of $20 \%$, for modified biomass $17.56 \%$ and for solar energy dependence only $3.8 \%$ which is the least amount. From the finding the relative price where the most determinant factor and also the community where sparely distributed which hinders the distribution of renewable Energy with the required speed. This article does not shows the region potential for developing renewable energy such as wind, biomass, solar and hydropower, dispersed throughout the Region, this potential has not been explored.
\end{abstract}

Keywords: Renewable Energy, Energy Demand, Benishangul Gumuz Region, Ethiopia, Model Village, Energy Intensity

\section{Introduction}

Renewable energy, often referred to as clean energy, comes from natural sources or processes that are constantly replenished. For example, sunlight or wind keep shining and blowing, even if their availability depends on time and weather. While renewable energy is often thought of as a new technology, harnessing nature's power has long been used for heating, transportation, lighting, and more [1], [2]. Wind has powered boats to sail the seas and windmills to grind grain [3]. The sun has provided warmth during the day and helped kindle fires to last into the evening. But over the past 500 years or so, humans increasingly turned to cheaper, dirtier energy sources such as coal and gas [3], [4].

Renewable energies are sources of clean, inexhaustible and increasingly competitive energy. They differ from fossil fuels principally in their diversity, abundance and potential for use anywhere on the planet, but above all in that they produce neither greenhouse gases which cause climate change nor polluting emissions. There are many forms of renewable energy. Most of these renewable energies depend in one way or another on sunlight [5], [6].

Wind and hydroelectric power are the direct result of differential heating of the Earth's surface which leads to air moving about (wind) and precipitation forming as the air is lifted [7], [8], [9].

Solar energy is the direct conversion of sunlight using panels or collectors. Biomass energy is stored sunlight contained in plants [9], [10].

There are a number of challenges that have hindered the development and full scale harnessing of some of the crucial energy resources in Benishangul Gumuz Regional State and all over Ethiopia. The more conventional challenges have to do with capacity barriers including technical, technological, economic and institutional weaknesses [10], [11].

The originality of this paper consists in the investigation of, 
challenges and the corresponding determinant factors which expresses the energy consumption and economic growth generates on short and long run a causal relationship between their components, such as the availability of the energy resource, relative prices and the financial development of the region/the community has been investigated.

\section{Results and Discussions}

The latest datasets available on the Ethiopian renewable energy source for the region under case study (2008-2016) were employed, which allowed us to include Benishangul Gumuz Regional State in the study among the other 9 regions of Ethiopia. Meanwhile Metekel zone and Assosa Zone selected Woredas are independently identified. In addition, using indicators such as: energy intensity, energy productivity, energy dependence, and resource productivity, allowed the energy performance measuring in the economy. The common period of data availability is $2008-2016$.

Table 1. Average energy intensity and energy consumption per inhabitant [11]

\begin{tabular}{llll}
\hline Zone & & Energy intensity & Total energy consumption per inhabitants Kwh/day hhousepopinhabitant \\
\hline \multirow{3}{*}{ Metekel } & Bullen & 12.5 & 0.12 \\
& Wombera Debate & 15.6 & 0.5 \\
& Debate & 13 & 0.12 \\
\multirow{3}{*}{ Assosa } & Assosa & 18 & 0.8 \\
& Bambasi & 16 & 0.61 \\
& Sherkole & 12.2 & 0.1 \\
\hline
\end{tabular}

\section{Estimation of Household Electricity Demand}

Estimation of the load is simply calculating the most probable demand of electricity load for the case study under investigation. As a result the daily energy demand of the case study, the peak hours of the required energy consumption for the analysis and estimation of the total daily energy demand of the households [12]. This scenario investigates depending on the secondary data source of NSMA and data from regional perspective.
In order to roughly estimate the total daily total energy demand one sample kebele where randomly selected and all the energy would be summed up. Table 2 shows the energy demand of each institution and the number that those institutions are found in the village. As it is clearly seen in the table, the large amount of the energy is allocated to the residents' purpose.

In actual case the load of the energy demand of the selected kebele is not real; instead it would be calculated by HOMER by considering the entire peak hour factor. Therefore the amount given here is used for rough estimation and for checking the deviation of the final value.

Table 2. Rough Estimation of Total Daily Average Energy Demand of Selected kebele.

\begin{tabular}{llll}
\hline Name of institutes need energy & No of institutes & Energy demand $(\mathbf{k W h} / \mathbf{d})$ & Total energy demand $(\mathbf{k W h} / \mathbf{d})$ \\
\hline House holds & 1253 & $10.2 \mathrm{~kW}$ & 12780.6 \\
Shops, Cafeterias, Barbers & 27 & Given as total & 253 \\
Government offices & 4 & 15 & 60 \\
Milling houses & 14 & 21.2 & 296.8 \\
Hospital, Clinics and Veterinary centers & 3 & 48,21 and 15 & 30 \\
Schools & 3 & 98 & 110 \\
Total & & & 13584.4 \\
\hline
\end{tabular}

According to the literature review $[5,8,12]$, there are many recent contributions addressing various connections of the energy sector. Most of these researches are in the field of the economic growth and energy taxation issues throughout the country which has to be extended to regional level, trying to assess the limits of energy taxation as a factor positively correlated with development, and, more specifically, to sustainable development, as the mankind aggression towards the planetary environment represents an incontestable reality.

The first studies in this field were conducted from a local perspective, focused on a comparison between the results of variables and data series stated on Table 2. As the above table 2 shows that the Average energy intensity and energy consumption per inhabitant where relatively larger in Assosa as compared to the other Woredas existing in the region. As the result depicted on the above table 2 most of Economywide targets for primary energy sources which has not been widely practiced. Only $13 \%$ of primary energy sources where used by the inhabitants under case study. With nearly throughout the hole years targeted the government shows nearly slower target for renewable energy. 


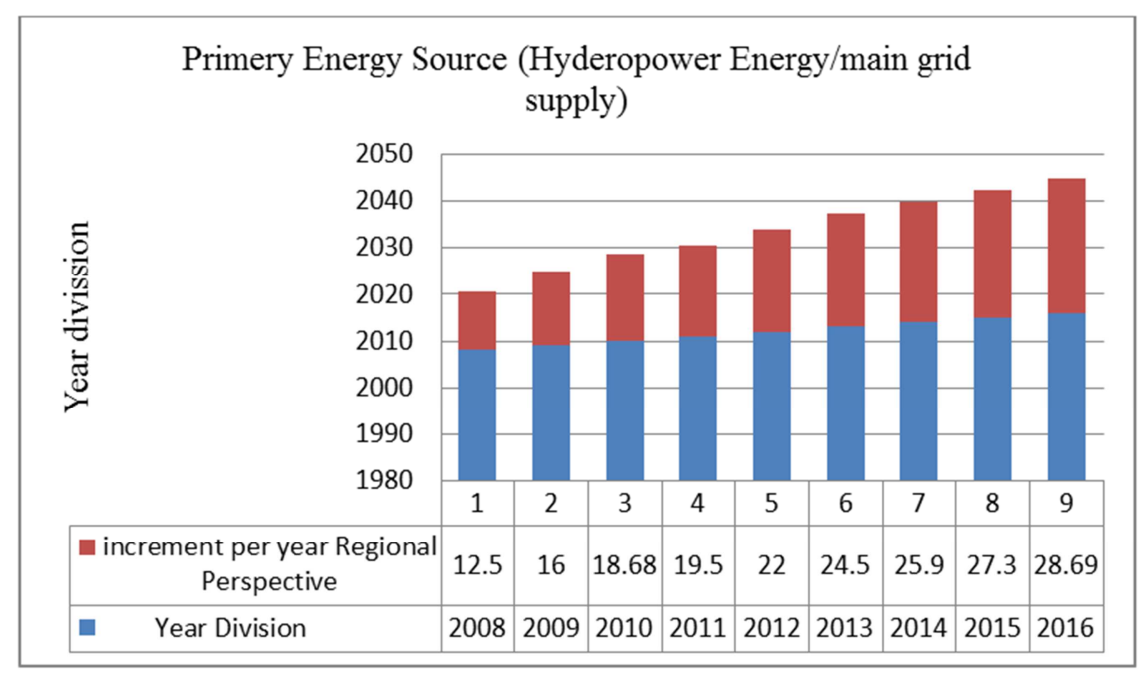

Figure 1. Primary Energy Source (hydropower Energy/main grid).

The analysis shows only $2.34 \%$ increment year to year where shown for having some form of Renewable energy use increment within 9 years and also renewable power has received less attention. But the result on figure 1 states that the government targets mainly on main grid supplied energy dissemination which increases with the percentage of 26.4 $\mathrm{Kwh}$ of energy within 9 years span. While the analysis shows the increment of the domain energy source i.e. supply of energy from main grid to the house holds from year to year. These may challenge the opportunity to find other source of energy easily and affordably.

The intensified application of main primary source of energy was the most dominant source of energy of the selected site. As depicted on Appendix 1.7 relatively more grid dependant energy sources are found in which the amount of net energy extracted from hydropower covers mostly $58.59 \%$ of the total energy. Also as stated on Appendix 1.7 the inhabitants mostly relay on gas oils for energy sources with the percentage of $20 \%$, for modified biomass $17.56 \%$ and for solar energy dependence only $3.8 \%$ which is the least amount. On the other hand, is known to be more appropriate for rural situations where grid connection is often problematic due to poor infrastructure and dispersed pattern of most of the rural settlements. It must also be underscored that comparison of cost between the grid and stand-alone systems of electricity supply is totally irrelevant for those pockets of remote areas that can barely or never be connected to the grid.

The consumers' willingness to pay for a product is an appropriate basis for determining on pricing and investment policies for rural electrification. In extending electrical power to low income areas where domestic consumers are poor and the demand of electricity for productive purposes is inattentive; low levels of demand, low revenues, and high initial costs are obstacle to investment.

The survey indicates that the key constraint to energy supply for rural communities is access to the initial capital needed to buy the equipment to harness the resource. This forced rural communities to choose energy options that are cheap on a day-to-day basis, but offer poor quality energy and are expensive over the longer term. It is obvious that electricity from the grid is cheaper when compared to, for instance, that generated by photovoltaic (PV) system or any other source of modern energy generation systems.

\section{Conclusion and Recommendation}

\subsection{Conclusions}

Rural areas in Benishangul Gumuz region are characterized by either low-density settlement with relatively large distances between households, or villages with fewer inhabitants in which the inhabitants are far from the main national grid with lower access of renewable energy. This has hindered the use of modern sources of energy as investigated from the survey. Leaving rural inhabitants, to continue on the course of the current use pattern of traditional energy sources, is bound to have highly negative consequences for the rural economy at large, as well as the environment and the ecosystem balance. Fortunately, the natural resource base for the generation of modern sources of energy is plenty. There are also favorable economic, environmental and energy policies. From the research it is concluded that the inhabitants' energy sources are mostly relay on national grid energy supply. There are other source of energy (like modified biomass energy sources, solar energy sources, and micro hydropower energy sources) which does not given due attention by the concerned body.

\subsection{Recommendations}

The following pointes are recommended for further work:

a) It is evident that the stand-alone system is most appropriate to rural electrification in the dispersed areas of the settlements in Benishangul Gumuz region.

b) Since the affordability of the price to people living in rural situations remains the major challenge and determinant factor to the dissemination of the technology.

c) It is thus recommended that the government, non- 
governmental organizations and the public make concerted efforts to overcome this challenge by using more flexible approaches to improve the current dreadful state of rural electrification in Ethiopia.

d) Further research may be done depending on the wider coverage of the study area. Since this research mainly focuses on one reference kebele to investigate the overall factors associated with other reference Woredas at large.

\section{References}

[1] S. C. Bhatia, R. K. Gupta (2018), "Textbook of Renewable Energy", Delhi: Woodhead Publishing India PVT. Limited

[2] Pirlogea C, Cicea C. Econometric perspective of the energy consumption and economic growth relation in European Union. Renewable and Sustainable Energy Reviews 2012; 16 (8): 5718-5726.

[3] Lee CC. Energy consumption and GDP in developing countries: co-integrated panel analysis. Energy economics 2005; 27 (3): 415-427.

[4] Engineering and Consulting Firms Association, J. 2007. "PreFeasibility Study for Rural Electrification Program by Renewable Energy in the Mountainous Region of Northern Samar in the Philippines".
[5] W. Woldegiorgis; 1988 "Wind Energy Survey in Ethiopia" Journal of Solar \& Wind Technology Vol. 5.

[6] Renewable Energy: The Clean Facts: https://www.nrdc.org/stories/renewable-energy-clean- Power Sector Policy and Legal

[7] Sharew Anteneh (2007), "Solar energy assessment in Ethiopia Modeling and Measurement";

http://etd.aau.edu.et/dspace/bitstream/123456789/239/1/Share w\%20Anteneh.pdf

[8] Getachew Bekele (2009), "Study into the potential and Feasibility of a Standalone Solar-Wind hybrid electric energy supply System"; Available at, http://www.divaportal.org/smash/get/diva2:282919/19/FULLTEXT01, viewed on March 2019

[9] HOMER National Renewable Energy Laboratory (NREL); 20061617 Cole Boulevard Golden, CO, 80401. http://www.nrel.gov/homer

[10] Mekuria: Ethiopia Power Sector Overview.pdf; Viewed on May 2018.

[11] Benishangul Gumuz Regional State Demography; Available at https://en.wikipedia.org/wiki/Benishangul-

Gumuz_Region\#Demographics, Viewed on April 2018.

[12] Moges Berebero (2012), Personal communication with Moges Berebero, Hydro Geo informatics technical person at Nile Basin Authority, 2018/19. 